\title{
READY: a web-based geographical information system for enhanced flood resilience through raising awareness in citizens
}

\author{
R. Albano ${ }^{1}$, A. Sole ${ }^{2}$, and J. Adamowski ${ }^{3}$ \\ ${ }^{1}$ DICEM, University of Basilicata, Potenza, Italy \\ ${ }^{2}$ School of Engineering, University of Basilicata, Potenza, Italy \\ ${ }^{3}$ Bioresource Department, McGill University, Montreal, Canada \\ Correspondence to: R. Albano (albano.raffaele@tiscali.it, raffaele.albano@unibas.it)
}

Received: 15 January 2015 - Published in Nat. Hazards Earth Syst. Sci. Discuss.: 4 February 2015

Accepted: 26 June 2015 - Published: 29 July 2015

\begin{abstract}
As evidenced by the EU Floods Directive (2007/60/EC), flood management strategies in Europe have undergone a shift in focus in recent years. The goal of flood prevention using structural measures has been replaced by an emphasis on the management of flood risks using nonstructural measures. One implication of this is that public authorities alone not only take responsibility for flood management. A broader range of stakeholders, who may personally experience the negative effects of flooding, also take on responsibility for protecting themselves. Therefore, it is vital that information concerning flood risks is conveyed to those who may be affected in order to facilitate the selfprotection of citizens. Experience shows that problems persist even where efforts have been made to communicate flood risks.

There is a need for the development of new tools that are able to rapidly disseminate flood-risk information to the general public. To be useful these tools must be able to present information relevant to the location of the user. Moreover, the content and design of the tool need to be adjusted to laypeople's needs. Dissemination and communication influence both people's access to and understanding of natural risk information. Such a tool could be a useful aid to effective management of flood risks.

To address this gap, a web-based geographical information system (WebGIS) has been developed through the collaborative efforts of a group of scientists, hazard and risk analysts and managers, GIS analysts, system developers and communication designers.

This tool, called "READY: Risk, Extreme Events, Adaptation, Defend Yourself", aims to enhance the general public
\end{abstract}

knowledge of flood risk, making citizens more capable of responding appropriately during a flood event. The READY WebGIS has allowed for the visualization and easy querying of a complex hazard and risk database thanks to a high degree of interactivity and easily read maps. In this way, READY has enabled fast exploration of alternative flood scenarios or past calamitous events. Combined also with a system of graphic symbols designed ad hoc for communication of selfprotection behaviours, it is believed READY could lead to an increase in citizen participation, informed discussion and consensus building.

The platform has been developed for a site-specific application: the Basilicata region, Italy, has been selected as pilot application area. The goal of the prototype is to raise citizen awareness of flood risks and to build social capacity and enhanced resilience to flood events.

\section{Introduction}

In spite of ongoing efforts to decrease vulnerabilities to natural hazards, the damages resulting from flooding remain high in Europe (e.g. IPCC, 2007). After each flood event the general public question the cause of the flood and ask why there were such tragic consequences. Often the blame is placed on the occurrence of extreme and unpredictable weather. However, trends in meteorological data show that these extreme weather events are becoming the norm rather than being the exception. The implication of this is a corresponding increase in flood and landslide events as evidenced in the EM-DAT International Disaster Database. In addition, some practices 
within watersheds are amplifying the damage potential when extreme weather does occur. These practices include inobservance of river regulations, urbanization developments and social and economic growth (e.g. Büchele et al., 2006; Fuchs and Holub, 2007). These practices could be symptomatic of a lack of knowledge about the risks associated with the practices and an absence of a culture of self-protection.

In this context, the concept of resilience has gained recognition due to the emphasis it places on the ability of communities to learn how to cope with unanticipated hazards. The concept of resilience to natural hazards builds on three pillars: resistance, recovery and adaptive capacity (Thieken et al., 2014). Adaptive capacity is the ability of a system to learn from past events and to adapt in such a way that it develops beyond the pre-event status (Thieken et al., 2014). According to Dovers and Handmer (1992), this proactive understanding of resilience accepts forthcoming changes in the system and aspires to adjust to new conditions. In the context of community resilience, it includes the willingness and the ability of a community to learn and adjust to changes (Watts and Bohle, 1993; Klein et al., 2003). Learning processes can have several facets including adaptation as a response to perturbations, self-organization, adaptive management and the use of all kinds of knowledge and innovation (Folke et al., 2005; Folke, 2006; Berkes, 2007; IPCC, 2007). An important step to achieve disaster risk reduction is to improve resilience to floods by achieving acceptance amongst the public of their own role in flood-risk management. The provision of information that promotes risk awareness could help to achieve this goal. Indeed, methods and technologies for realizing adequate and effective communication between decision makers and the public at large are keystones of flood-risk management plans currently being prepared across Europe and is a requirement for compliance with the EU Floods Directive 2007/60/EC (EC, 2007).

According to Renn (2008, p. 207), risk communication can enhance people's knowledge about a risk, persuade them to change their attitudes or behaviour, promote confidence in the responsible authorities and provide the conditions for an effective stakeholder involvement in risk issues.

Today, although the authorities responsible for risk management have institutionalized plans for the communication of flood risk, communicative practices often appear to be focused on the role of government rather than the individuals at risk. A "people-centred" approach, in which communities have input in the design and operation of the system (Sene, 2008), is now recognized as important in order to involve communities in flood-risk management. Communication is not a straightforward process of delivering information; it must also be effectively received by someone. Therefore, a risk communication can be defined as successful when all the information useful to encourage good practice of safety is transferred to the public with the result that they react actively and immediately to a state of alert.
There are no "one-size-fits-all" solutions to designing effective flood communications. Multiple dissemination channels, tailored to a specific person and area while considering local social and cultural context, are essential for effective communication (O'Sullivan et al., 2012).

The three levels of communication, functional, iconic and symbolic, often intersect, giving rise to complex communication devices. Before transmitting a communication it is worth giving thought to which type of communication may be the most appropriate. In the context of the communication of risk, prescriptive texts, diagrams, illustrations, icons, videos, sounds, colours and shapes are communication options that might be considered for use in different situations. By providing a visual image of the predicted consequences of flooding, flood hazard maps can enhance people's knowledge about flood risk, making them more capable of an adequate response (Kjellgren, 2013).

However, the content and design of much existing software that utilizes maps are not adjusted to laypeople's needs and therefore the software's awareness-raising capacity is limited (Kjellgren, 2013). Few studies focus on how maps are disseminated and communicated to the public. As dissemination and communication influence both people's access to and understanding of flood risk, this appears to be a significant omission. In this light, owing to recent technological developments, web mapping applications have become readily useable as information dissemination tools and their implementation for the purpose of disseminating heterogeneous hazard and risk geographical information is now feasible (e.g. Müller et al., 2006; Douglas et al., 2008; Le Cozannet et al., 2014). A web-based geographical information system (WebGIS) can constitute a new and powerful tool when it comes to risk communication and management dia$\log$. Not only can it enhance recipients' knowledge resources and thereby facilitate informed discussion, but it can also increase individuals capacity to plan their own protection.

In this light, the potential of the WebGIS is presented in Sect. 3 after a review of the state of the art (Sect. 2). In Sect. 4, the principles and system design of the developed WebGIS, called READY, is presented. In Sect. 5, the READY's site-specific application, an experimental system tested in Basilicata region, is described. Finally, Sect. 6 describes the overall conclusion.

\section{State of the art}

Several WebGIS tools have been developed in order to disseminate data and information that aim to enhance natural hazard management.

For example, the Lav@hazard tool (Vicari et al., 2011) is focused on the development of services for the integration of heterogeneous remote-sensing data to quickly assess volcanic hazards and disseminate this information to affected parties. Such tools have proved useful to disseminate infor- 
mation about the threats of volcanic processes in order to support the people in charge of safety planning when choosing the appropriate prevention and mitigation strategies.

Le Cozannet et al. (2014) have designed a WebGIS that aims to manage and visualize a volcanic risk geographical database. This tool is designed to support both the prevention and risk mitigation phases (long-term anticipation of a potential crisis) and the response and recovery phases. The latter is achieved by providing information to the public about critical infrastructures and their utility during the crisis (e.g. potential for a recreational area to serve as shelter for displaced people). This information allows those at risk to make a more informed decision when deciding on evacuation routes for themselves and their families.

Other WebGIS tools (see for example Frigerio and Westen, 2010; Kos et al., 2009) are proposed as learning and training platforms. These tools aim to provide knowledge to aid in the management and reduction of risk but have remained primarily targeted to an audience of decision makers, scientists and civil security. Some of these tools, however, could be utilized by citizens during response and recovery phases (e.g. to provide real-time updates of the operational status of services or hazard assessment information; Le Cozannet et al., 2014).

\section{WebGIS as a tool for flood-risk communication to raise public awareness}

In the present study, a citizen-oriented WebGIS is proposed to enhance social learning in the specific field of flooding. This tool aims to support preparedness of the general public for a flood event by providing information that allows anticipation of the crisis in the shorter term.

WebGIS is efficient in achieving rapid results in shared understanding of natural risk issues (Frigerio and van Westen, 2010; Le Cozannet et al., 2014). The interactive, dynamic and flexible nature of the technology, combined with the immediacy with which information is presented by the map and graphic symbols, can facilitate and speed up the process of knowledge acquisition. A key strength of the technology is the way hazard scenarios, at-risk infrastructure and vulnerability and risk analysis are integrated in one accessible platform through which non-GIS experts are able to share and understand natural risk issues (Frigerio and van Westen, 2010). WebGIS can constitute a powerful tool when it comes to risk communication and management dialog (Le Cozannet et al., 2014). Not only can it enhance recipients' e-knowledge resources, thereby facilitating informed discussion and raising capacity for personal protection, but it can also provide a common visual basis for a two-way exchange about the local risk situation. Therefore, WebGIS has the potential to increase general public preparedness for a flood crisis and to increase the capacity of individuals to take measures to protect their lives, family and property.
The proposed WebGIS, called "READY: Risk, Extreme Events, Adaptation, Defend Yourself", is designed to support both citizens and civil security stakeholders (for example voluntary associations and civil protection organizations) and train them so they are prepared for flood events. It does this by allowing users to run mock flood events and understand the impact that their actions have on overall outcomes. The ultimate goal is to stimulate new flood management practices utilizing WebGIS to visualize and manage flood risk. Furthermore, WebGIS can support "place-based" methods in order to increase citizen participation and encourage active involvement in policy approach. Citizen participation in informed discussion can facilitate consideration of different management options. It can play an important role by both increasing understanding of risk management as a shared responsibility and building social capacity to respond to risk. In this way citizens, who are traditionally seen as simply victims of flood damage, could be transformed into active participants in risk governance as they take more responsibility for their own protection through planning for and acting during flood events.

The proposed Web-GIS focuses on raising awareness. According to O'Sullivan et al. (2012), awareness is an essential factor in a community's ability to adapt in response to natural events. Awareness levels are directly proportional to the provision of correct information and memory of historic events (Shen, 2009).

\section{Citizen-oriented WebGIS: principles and system design}

To date, much of the research conducted has centred on exploring ways to increase the public's awareness (Planat, 2004). In particular, consideration has been given to the methods in which the utilization of maps can increase understanding of risk perception (Meyer et al., 2012). Little attention has been given to the issue of how these maps are disseminated, explained or marketed to the public (Kjellgren et al., 2013). Considering that the way maps are disseminated, explained and marketed may have implications for people's understanding of the maps, this appears to be an important complementary perspective to investigate. According to Kjellgren et al. (2013), simply publishing hazard and risk maps is unlikely to lead to attitudinal or behavioural changes; this requires more interactive, dynamic and flexible communication tools and material or symbolic incentives. These maps cannot provide a complete picture of the risk issues, simply because there are too many possible combinations of data layers. GIS tools, conversely, are able to integrate, store, edit, analyze, share and display geographic data. They are specialized tools, however, and the general public are on the whole unfamiliar with how to use them. A webbased tool able to simplify visualization of complex hazard and risk databases for non-GIS experts could overcome this 
problem and allow the general public access to a wealth of useful information.

In the present study, a site-specific, citizen-oriented and web-based information system is proposed in order to promote shared knowledge among scientists, decision makers and citizens of flood hazard and risk. In order to take into account the key requirements of the READY platform users, i.e. citizens and operators that work in civil protection organizations, a group of cross-disciplinary experts were consulted (i.e. scientists, hazard and risk analysts and managers, GIS analysts, system developers and communication designers) who have been involved in previous projects to design tools using co-design and emphatic design processes. Co-design refers to a process that involves users alongside professional designers in the development of the system; emphatic design requires system developers to share the experience of end-users so that the developer gains insights into the problems and requirements as experienced by the intended user (Steen et al., 2007; Le Cozannet et al., 2014). The experts were involved in "living labs" throughout the participatory design process and in the building of the prototype to the point of testing in the Basilicata region, Italy. A "living lab" is a user-centred open-innovation ecosystem, operating in a territorial context (e.g. city, agglomeration, region), integrating concurrent research and innovation processes within a public-private partnership.

The READY platform was developed using open-source tools and libraries. It is composed of two main parts: an opensource database, i.e. "PostgreSQL" with its spatial extension "PostGIS", and the open-source user browsing component interface "MapServer" supported by "OpenLayers" libraries. The integration of the two parts aims to realize a powerful and easy-to-use tool that allows users to rapidly create a map tailored to their own requirements. The maps are created using the layers stored in the database or using layers created by the users with another GIS platform such as Google Earth or QuantumGIS. The users can upload a layer created with the latter software easily by dragging and dropping it into the READY interface. The users can query the database using a simple and user-friendly interface integrated into the platform.

The layout of the interface (Fig. 2) is designed using the method of "experimental graphic semiology" introduced by Fuchs et al. (2009). It is designed to enhance an individual's perception and understanding of the maps. The visual strategy (Fig. 1) chosen by the experts, and also in accordance with Fuchs et al. (2009), is composed of three clear sets of ocular movements: starting from the centre, i.e. the map canvas, the eye moves to the title and down vertically to the legend section and then comes back to the map canvas. If there is sufficient time, the additional marginal elements, i.e. scale bar, coordinate and measurements visual display unit, are explored. To realize this visual strategy the READY interface (see Fig. 2) has been designed such that

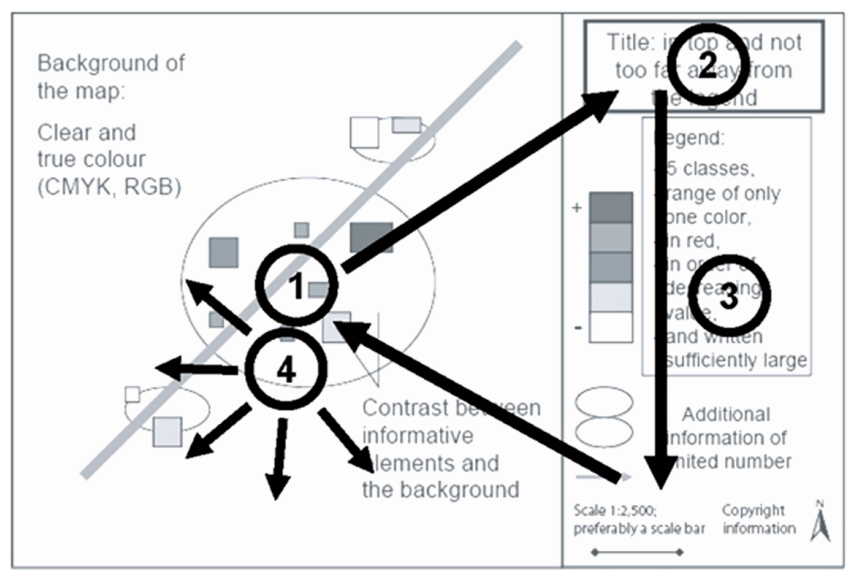

Figure 1. Schematic representation of the visual strategy introduced by Fuchs et al. (2009).

- the background of the map is clear and mostly in true colour (typically Google, Bing and OpenStreetMap base maps);

- the "transparency" tool included in the "style map" tool is designed such that there is a contrast between informative elements and the background;

- a sufficiently large legend on the right side of the GUI (graphical users interface) with a conservative amount of information is provided;

- additional information such as scale and coordinate visualization is provided on the down part of the right side of the GUI.

As the database behind the tool is very extensive, the information contained in the database has been organized into a number of data layers which can be turned on or off in the map interface individually by the user. In this way the user is able to select the information they wish to visualize. The layers are structured first by topic (cartography background, exposure and elements at risk, etc.) that are divided in turn into categories (e.g. land cover, transport) in which items, such as census area, bridges and culverts, are included.

\section{Usefulness and transportability of the READY WebGIS: site-specific functionality and customized tools}

The selected site for testing the capabilities of the READY platform was the Basilicata region in southern Italy (see Fig. 3). This region can reasonably be considered an area at risk of flooding. Indeed, the area has been affected in the past by a great number of flood disasters (AVI project, 2000). Furthermore, recent flood events that have occurred in the south-east of the region have shown the inadequacy of existing structural protection measurements and, hence, the 


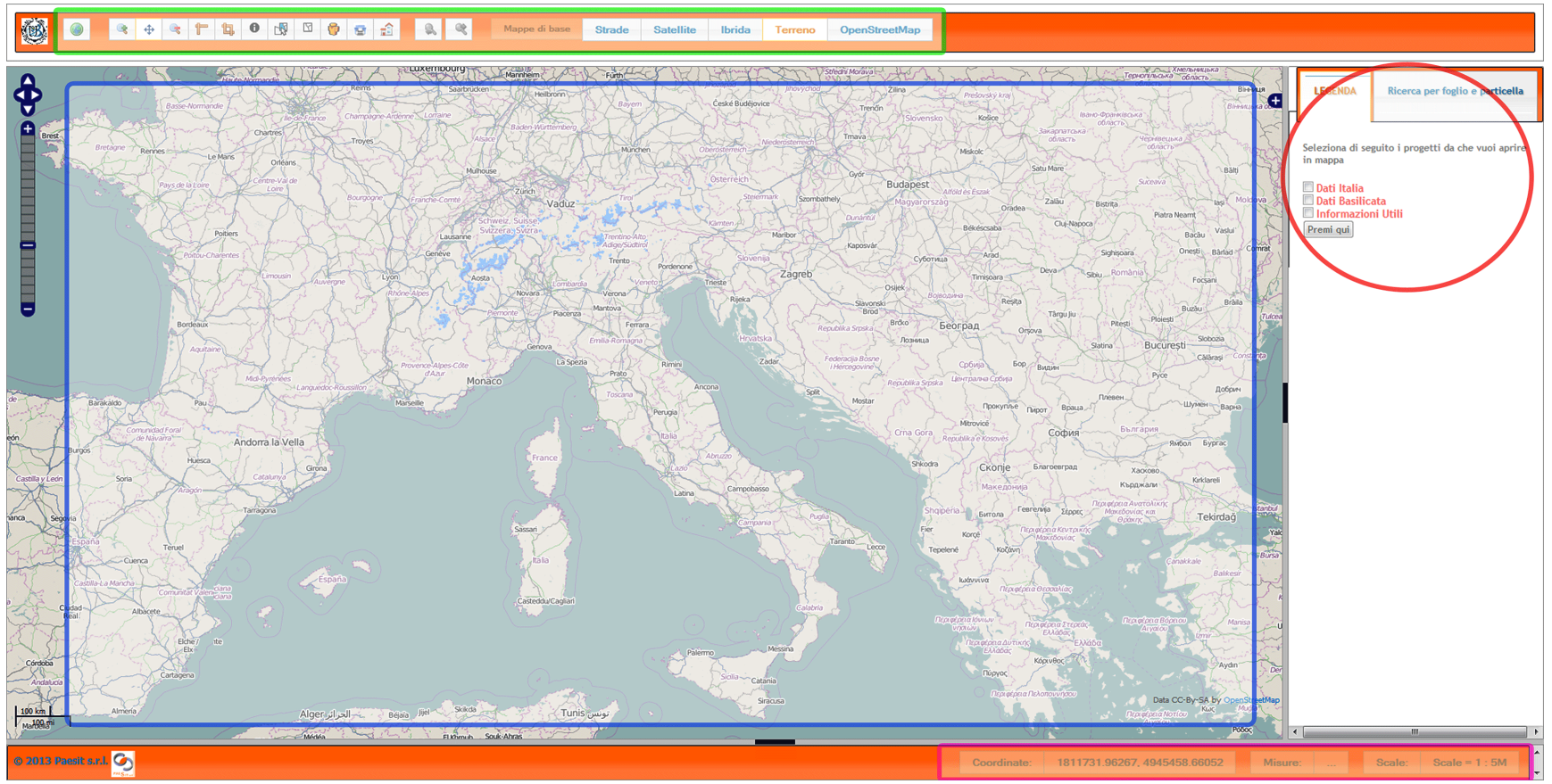

Figure 2. READY GUI designed on the recommendations of Fuchs et al. (2009).

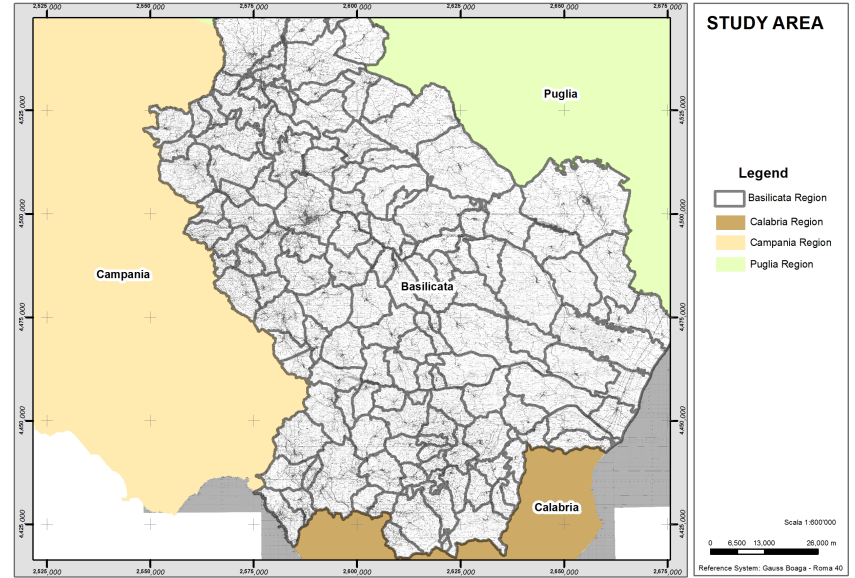

Figure 3. Map of the chosen study area (Basilicata region).

need for the development and use of non-structural mitigation strategies (Albano et al., 2014).

Within this context, the READY platform has been developed in order to increase the user's knowledge of flood-risk issues that affect this area. Site-specific application is necessary to bridge the gap between large geoinformation architectures and services. This site-specific application can increase the citizens' understanding of risk issues, which is mediated by existing beliefs and local knowledge.

The WebGIS includes four interdependent subsystems (see Fig. 4): (i) a target-oriented geodatabase supported by (ii) a historic events inventory; a user browsing interface that

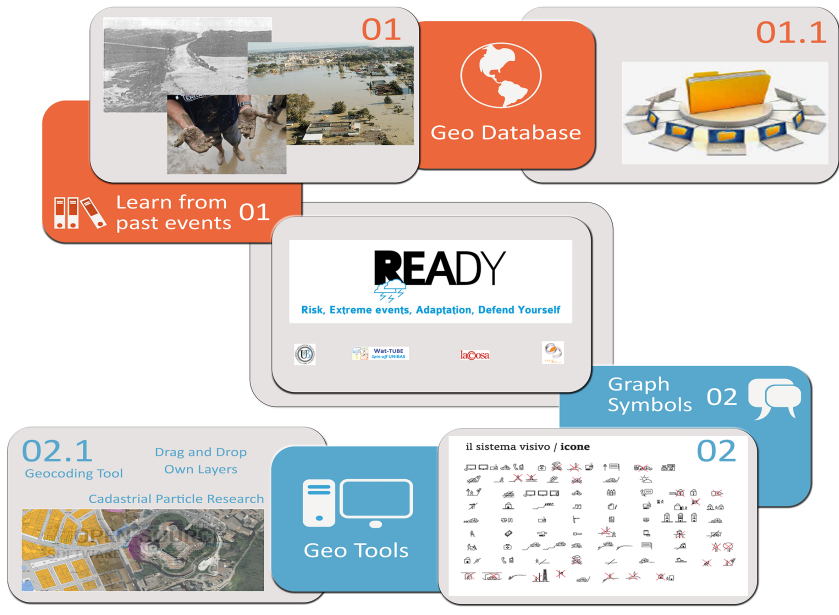

Figure 4. Schematic representation of the interdependent subsystems of READY.

integrates with (iii) a graphic symbols system; and (iv) customized tools, hereafter referred to as "geo-tools". These subsystems are described more fully in the sections that follow.

The WebGIS was based on a multi-scale and multilayer approach. The diverse information layers are visible only at the appropriate scale range in which they produce useful information (i.e. there is a scale-dependent visibility tool). Therefore, the tool can support citizen risk understanding at multiple scales, i.e. regional and microscale. Regional-scale approaches differ from microscale approaches in their need 


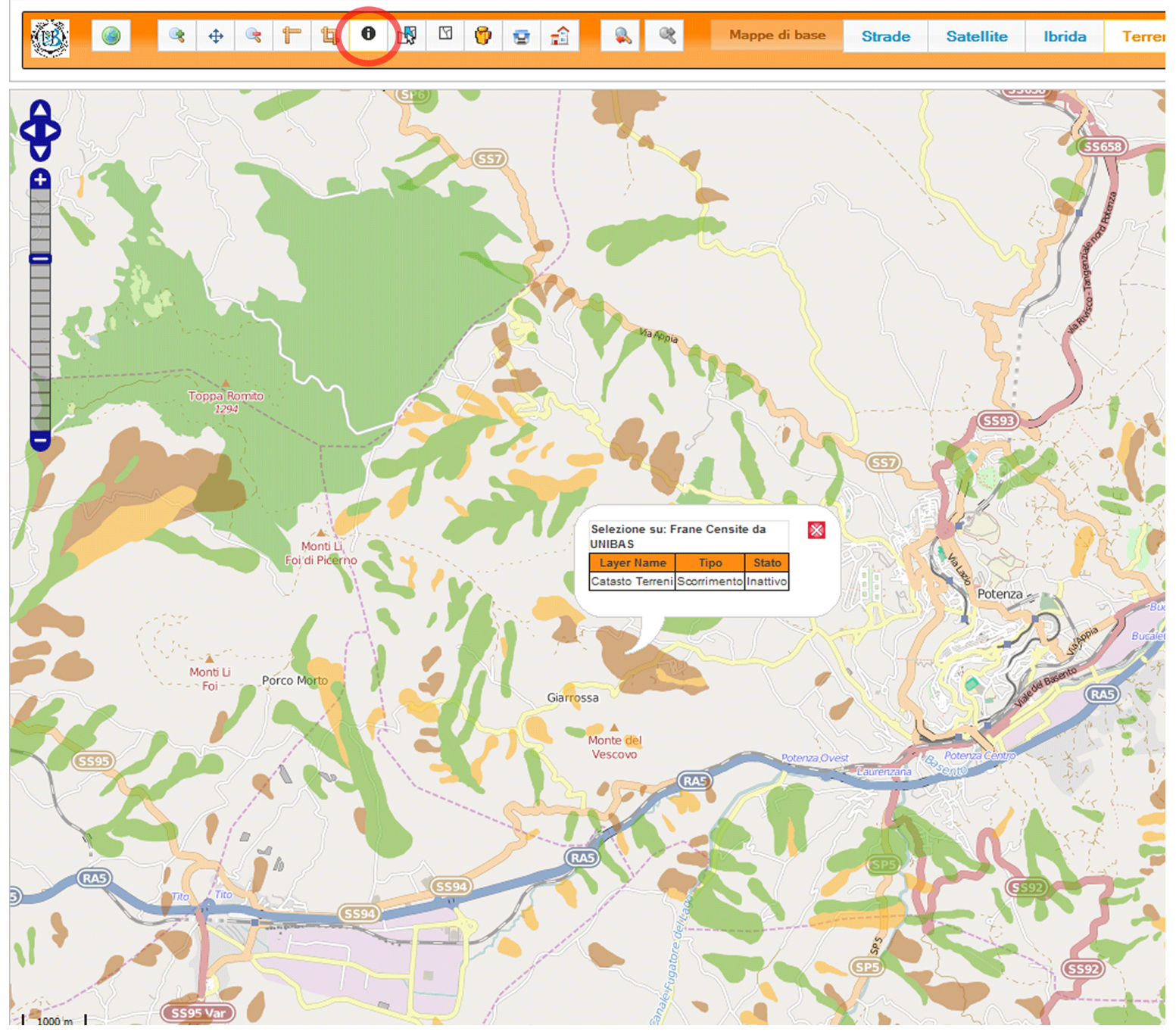

Figure 5. Screenshot of a landslide hazard map visualized in the READY platform.

for aggregation. The regional scale can show information about aggregation units at risk, e.g. residential areas, land use units and also administrative units (e.g. municipality). At the microscale the assessment is based on single elements at risk (building, infrastructure object, etc.).

\subsection{Target-oriented geodatabase}

The READY database includes the main meteorological and hydrological spatial data (meteorological stations inventory, isohyets map, rivers and dikes, hydrological basins and watersheds, and so on) that characterize the environmental variables typically required for flood hazard assessment in river basins. Also included are other layers that are relevant for describing the river basins such as a digital elevation model and landslide inventory map (Fig. 5). The background maps (e.g. Google satellite maps, OpenStreetMap layers) can highlight other geographical resources such as elements that could be potentially at risk (e.g. water supply network, strategic buildings, roads).

In addition, an inventory of exposed elements, particularly those of strategic and critical importance (e.g. bridges and culverts), has been included. Users can overlay the flood hazard map on the land use map and/or census area map to obtain information on the number of people potentially affected by the chosen flood scenario and classify them on the basis of age, gender, education and other demographic parameters (Fig. 6).

Spatial data for strategic and critical elements that cross the road networks, such as bridges and culverts, are supported by alphanumerical information, accessible through simple query. These data focus on an element's physical and hydraulic status, as evaluated by surveys and studies conducted by experts and researchers at the University of Basilicata. The most critical bridges and culverts, i.e. those that cross the road networks that are critical due to their struc- 


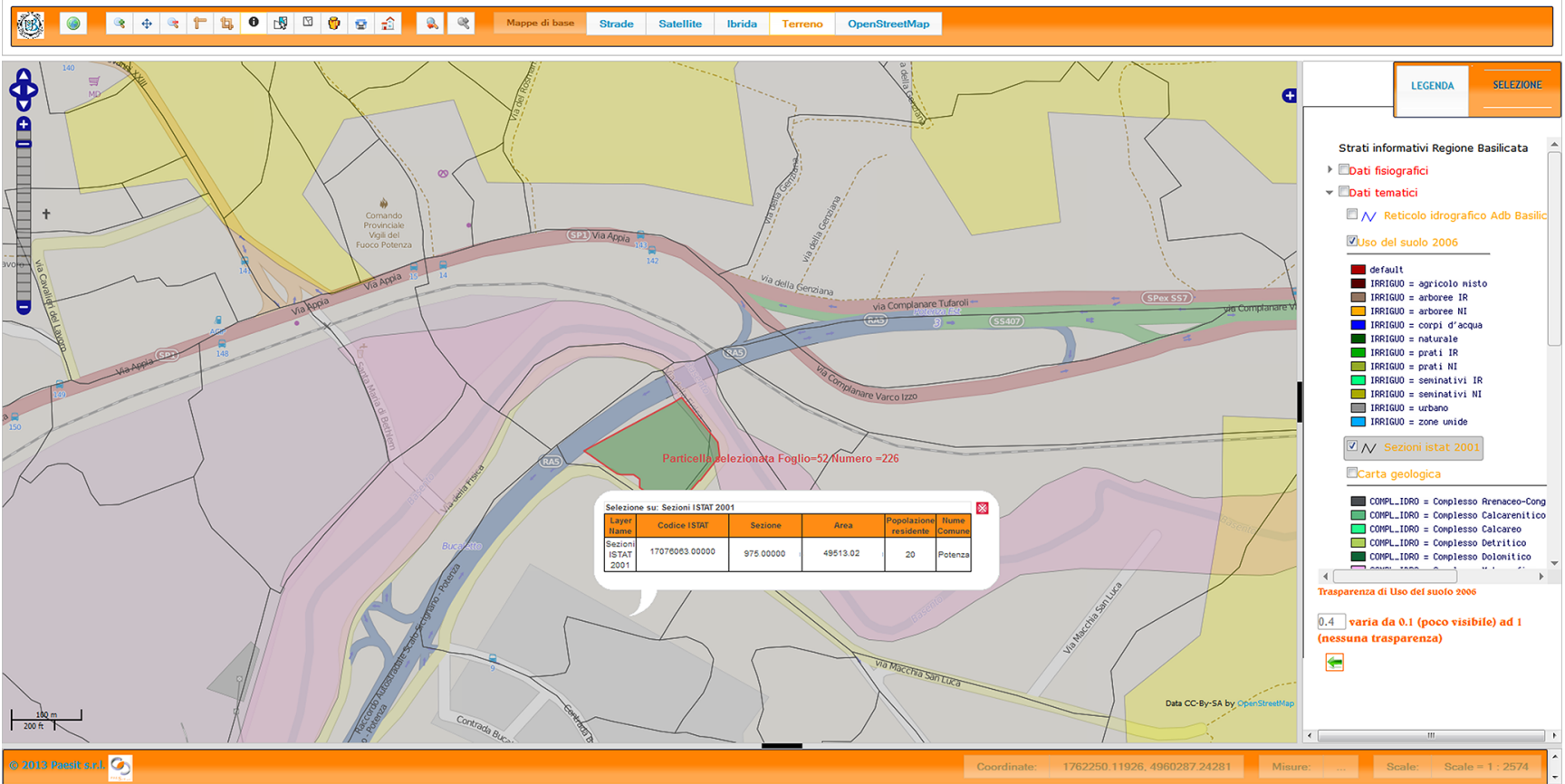

Figure 6. Example of a flood hazard map for a municipality within the Basilicata region, created by a user of READY. This hazard map is overlayed on the land use map, OpenStreetMap background map and census area map. The pop-up, in the centre of the figure, represents a query about the resident population in a selected census area.

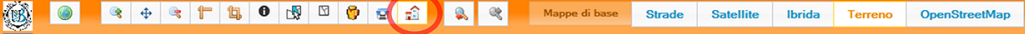

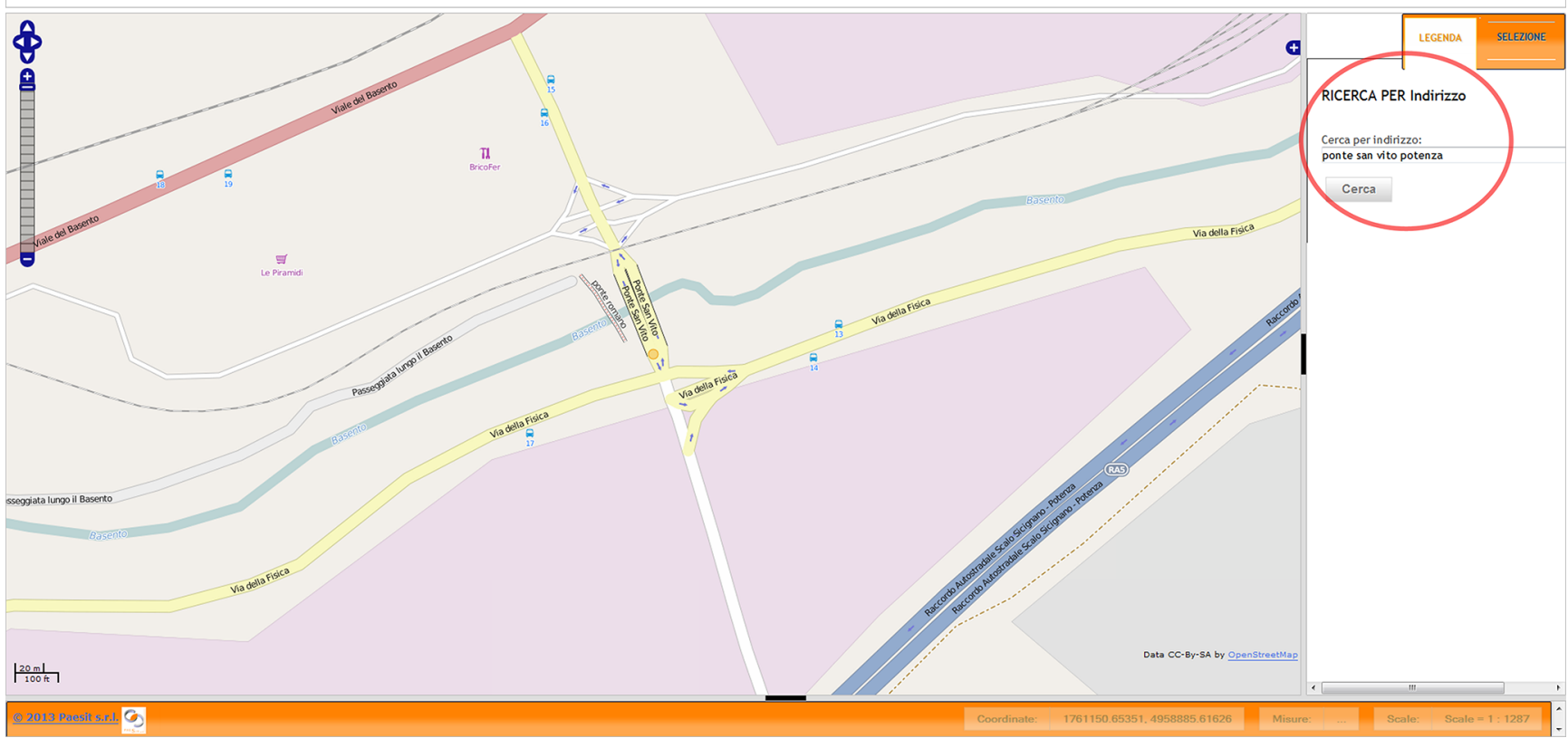

Figure 7. Example of the use of the Geocoding tool: shown is a search for the "S. Vito" bridge in the municipality of Potenza, Basilicata region.

tural status and/or being undersized and/or being obstructed by vegetation, can be shown on the map. Highlighting the most critical bridges and culverts is important for the pre- paredness of the civil protection operators when managing the emergency and can also help citizens plan evacuation routes during a flood. The visualization of this information 


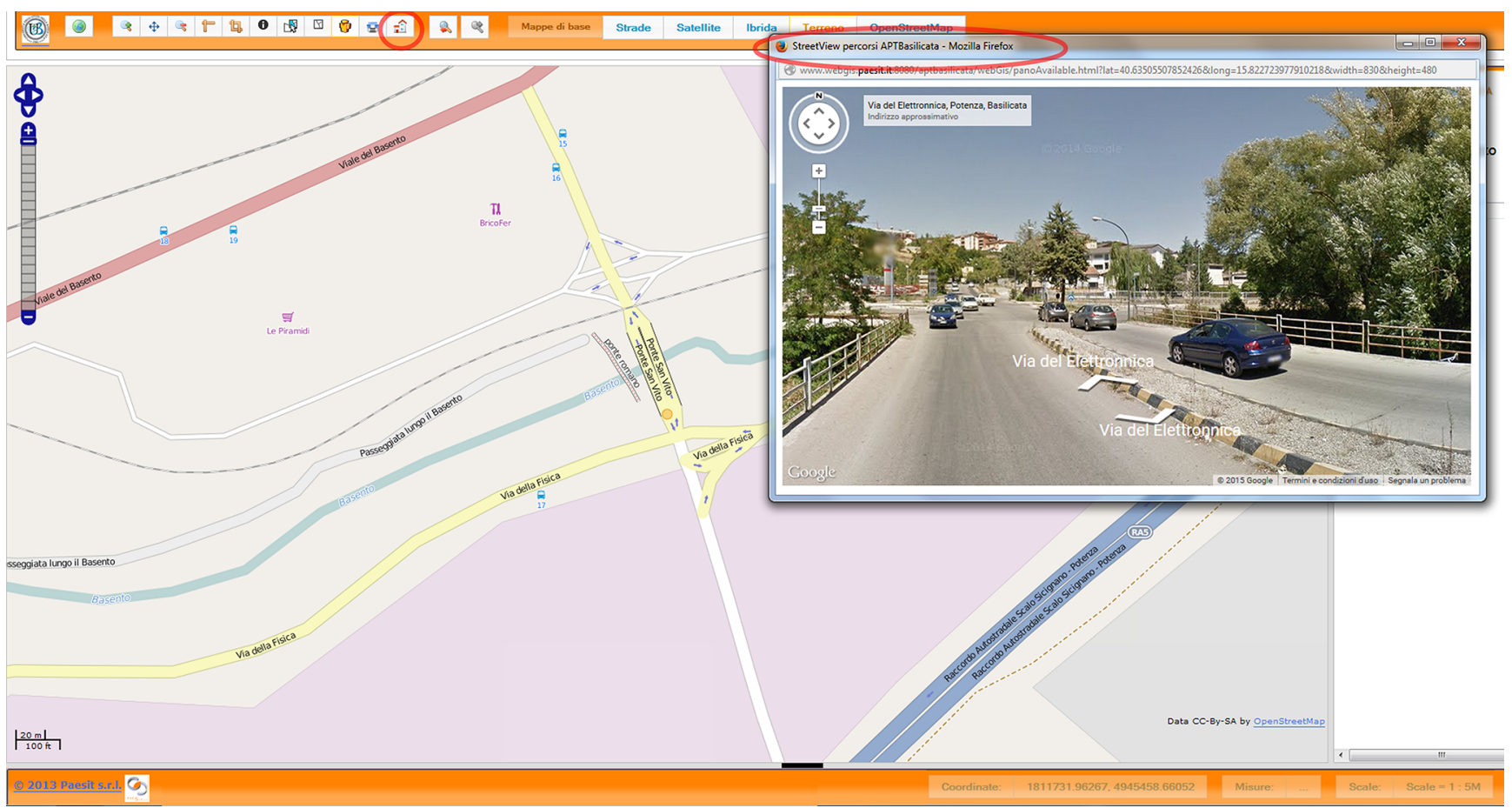

Figure 8. Visualization of the "San Vito" bridge by the Google Street tool.

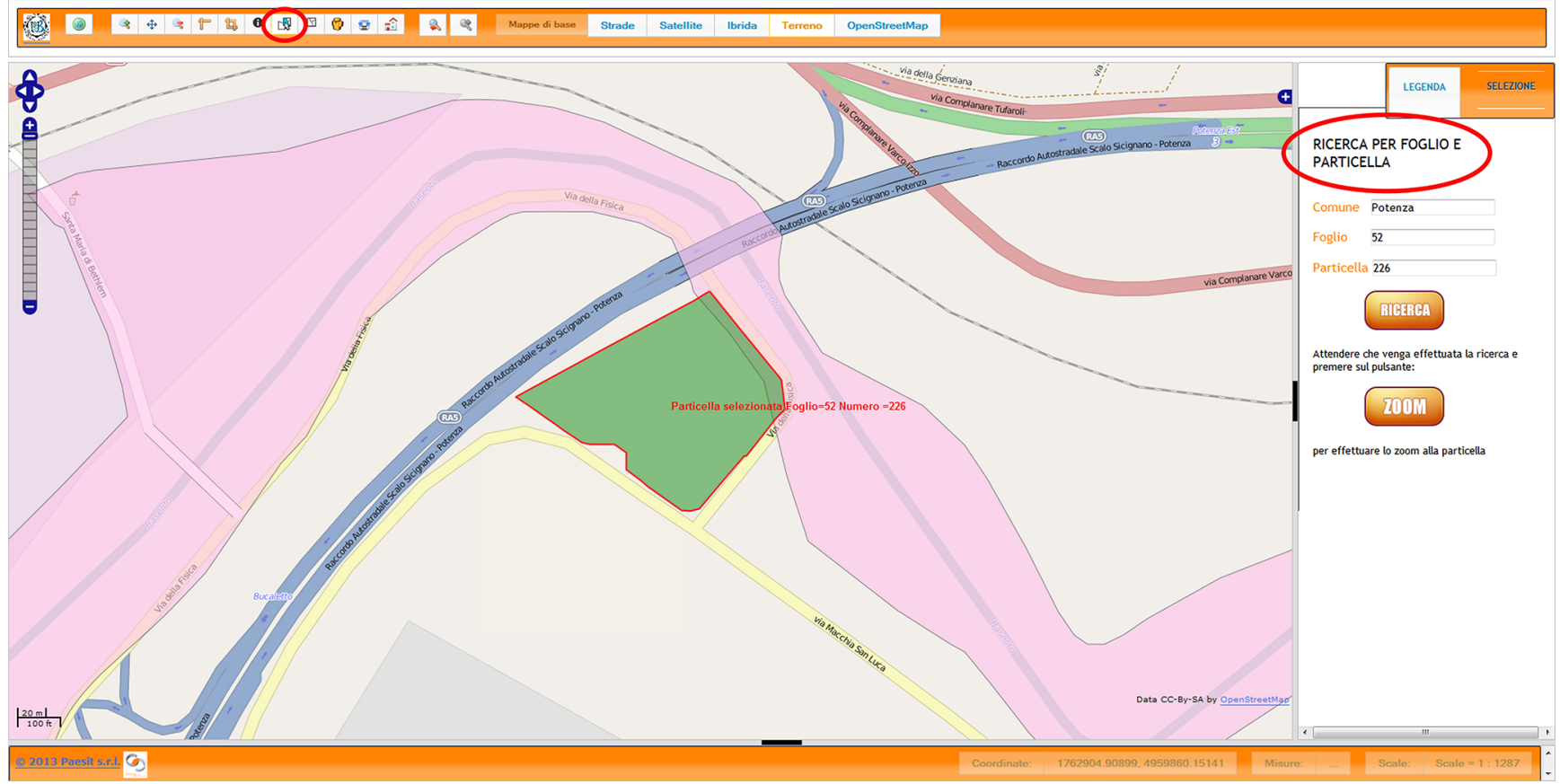

Figure 9. Example showing the cadastral particle in the Potenza municipality, used to check whether individual properties are in the flooded area.

represents an example of a project that aims to support the dissemination of the results of research studies in order to address the communication gap between scientists and citizens.
The bridges are displayed with different colours and symbols to indicate whether they are likely to be overtopped by water flow during different flood scenarios for a specific flood return period. This supplementary information (e.g. 


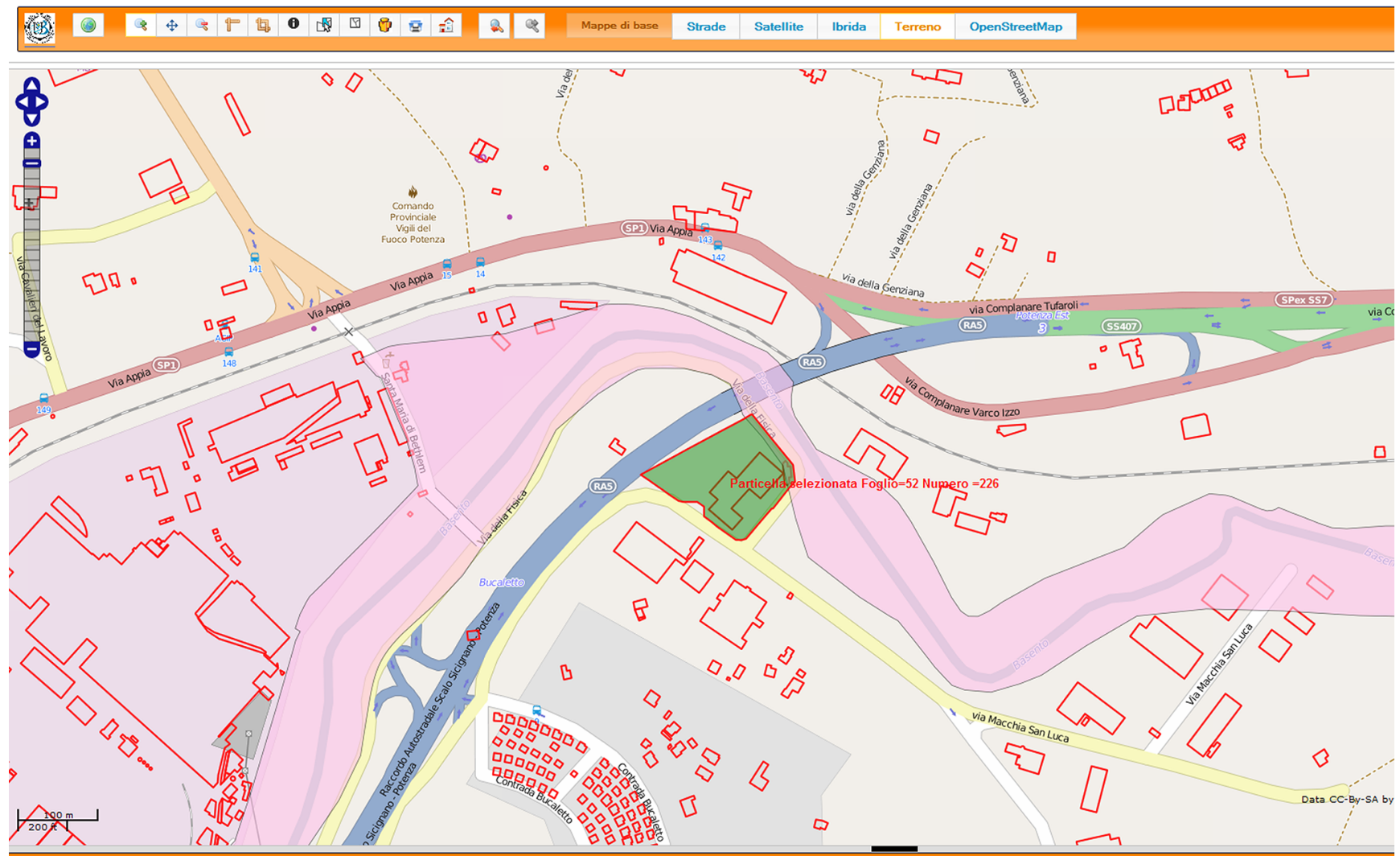

Figure 10. Screenshot of a flood-risk map composed of the flood hazard map superimposed on the Google background map, the cadastral particle and the municipality buildings map uploaded by the user by drag-and-drop. The area is selected using the "ad hoc" search tool.

bridges overtopped, water depth, flow rate in the cross sections) is included in order to improve the communicative effectiveness of the tool and overcome the limitation of the 2-D spatial representation. The main aim of the READY platform is to make data not only available but also accessible to users. The users, by superimposing a diverse range of map layers, can create tailored maps specific to their own requirements.

\subsection{Geo-tools for new learning experiences}

The proposed WebGIS is integrated with "ad hoc" research tools in order to increase its usability. The geo-coding tool, i.e. search-for-location tool, allows the user to easily identify a structure or infrastructure at risk in the map by searching for it using its address. For example, a citizen, superimposing the flood hazard map on one of the background maps, can promptly identify whether the place in which they live or work is likely to be flooded during a specific scenario by keying its address into the geo-coding tool form (Fig. 7). The Google Street View tool can help people plan for flood events by showing, for example, a road that should not be utilized during a flood as it is likely that a bridge will be overtopped (Fig. 8).

READY also makes it possible to explore the risks to a particular property through the simple and easy-to-use inter- face shown in Fig. 9. This is useful in order to check whether a person's own property would be potentially affected during several flood scenarios of different intensity. The platform is suitable for both basic and advanced users. A user with more GIS experience, as might be expected of some individuals involved in civil protection, can upload his or her own layer. This layer can be created by a stand-alone GIS (e.g. Google Earth or QuantumGIS) and integrated with the data and knowledge available through the READY database (see Fig. 10). The users can upload their own layers simply using a drag-and-drop technique.

Lastly, the measurement tools can help users to extract other geographical information, e.g. the distance of a building from the river or the area of a building affected by a flood scenario.

\subsection{Learn from historic events}

The group of experts involved in the design of the platform considered it essential to increase users' flood-risk perception by utilizing memory of historic flood events. To this end, the database includes an inventory compiled by IRPI ("Istituto per la Ricerca e la Protezione Idrogeologica") during the AVI Project (AVI database, 2000) of historical events occurring in the study site from 1918 to 2000 . READY allows 


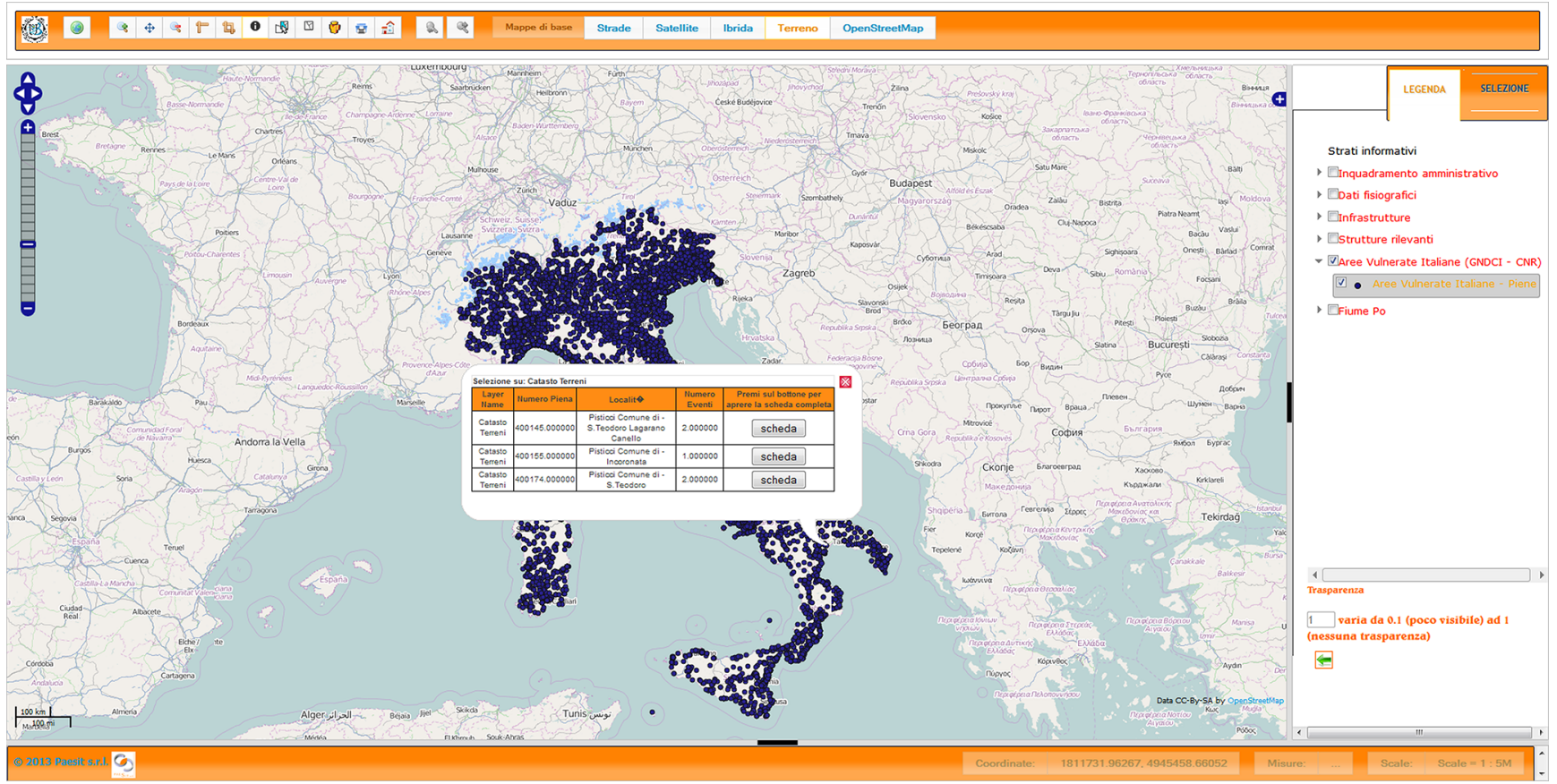

Figure 11. Search for the location of historical events that occurred in this area of Italy. Source: AVI project (2000).

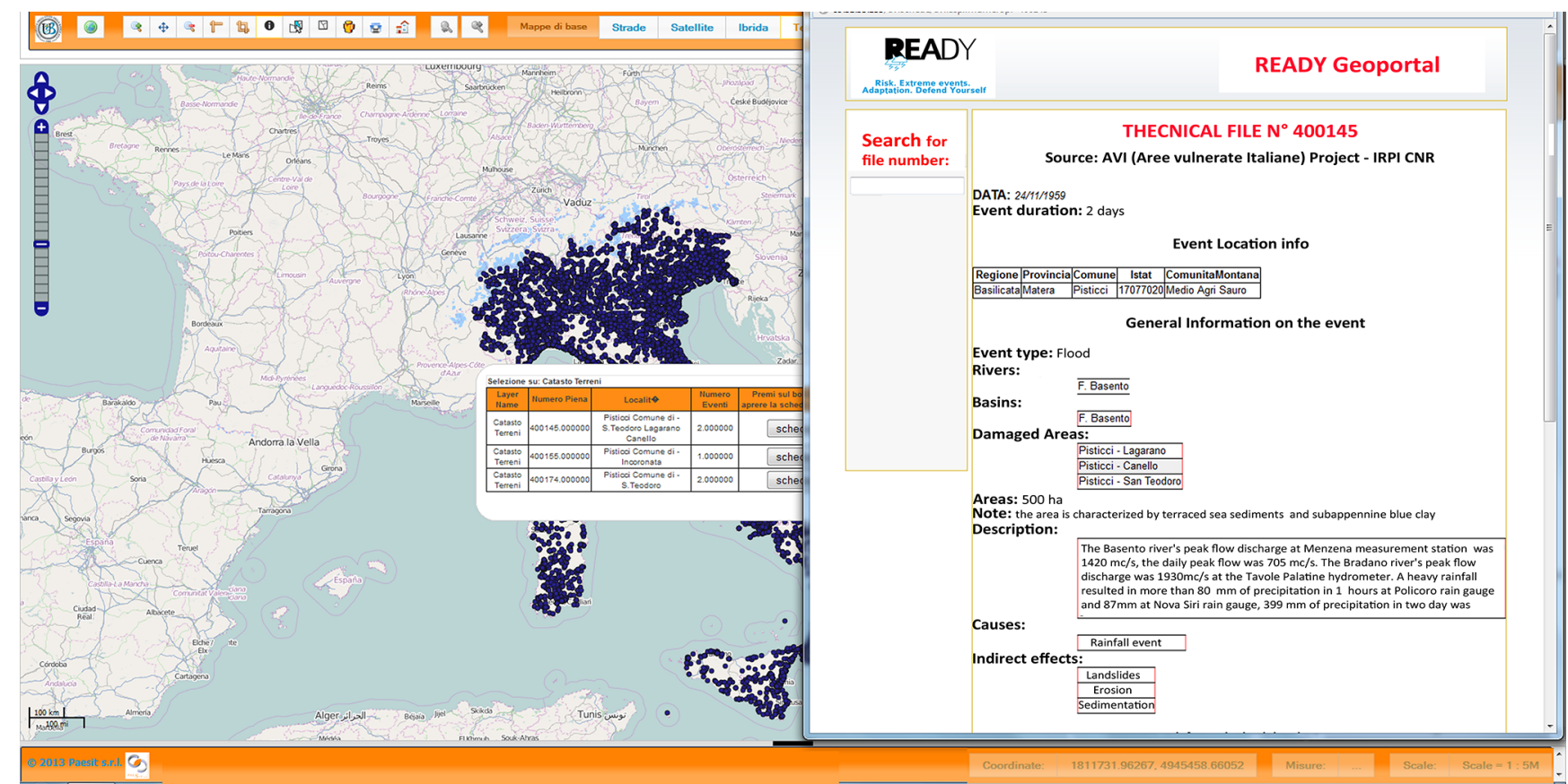

Figure 12. READY form for showing all the information of a selected historical event.

the user to identify and query these historic flood events by searching by location (Fig. 11) or by a specific event's identification number (i.e. the univocal number that characterizes each historical events, see Fig. 12). This geographic layer shows a wide range of information including date and duration of the events, people and area involved, economical and structural direct and indirect damages, and recovery actions implemented after the events. 

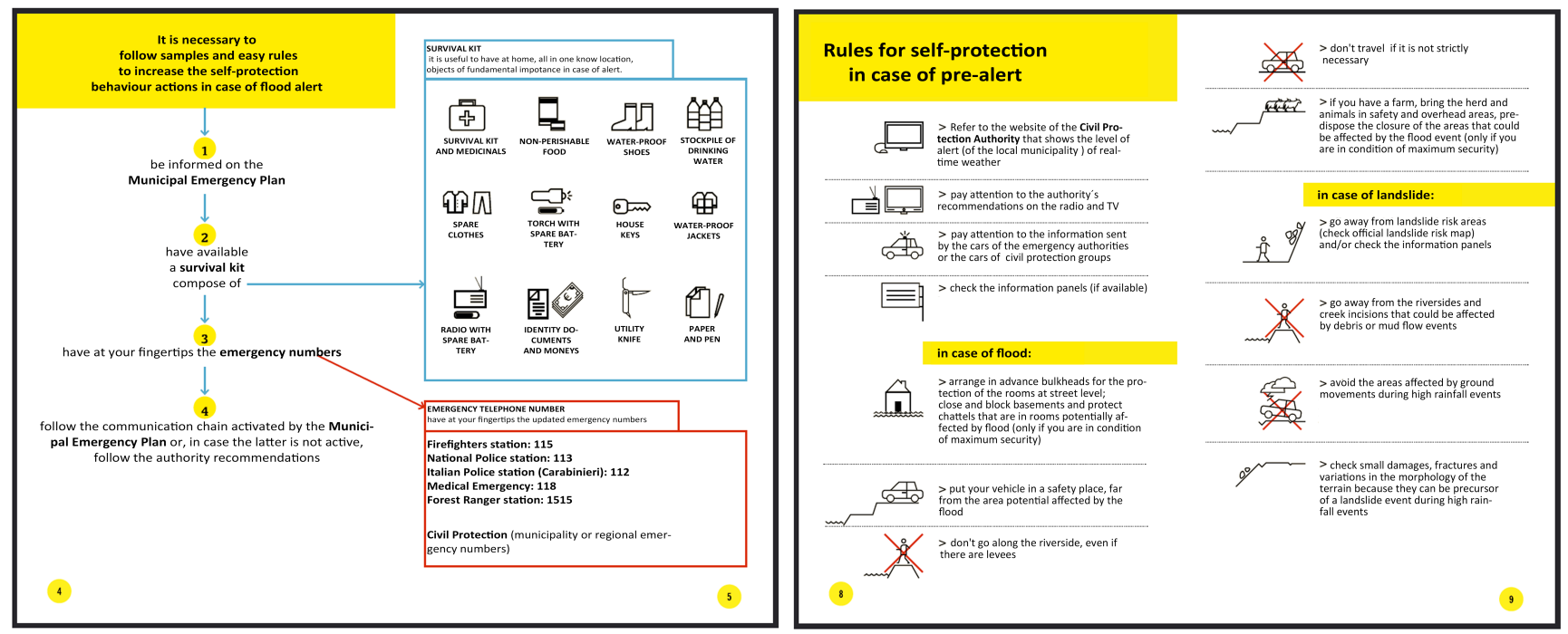

Figure 13. Example of the recommendations, provided by the READY platform, for behavioural actions in case of alert, intended for selfprotection enhancement.

\subsection{Graph symbol system}

Finally, the WebGIS is supported by a system of graphic symbols for the communication of self-protection behaviour actions in case of alert (Fig. 13). Although the authorities responsible for flood-risk management have implemented and institutionalized plans of communication and communicative practices for each stage of flood management, they are fragmented, with no common standardization of codes and an evident lack of coherence. We have developed a standardized system of graphic symbols that can be quickly interpreted and are properly contextualized to be more effective (Fig. 14).

\section{Discussion}

Risk communication is a key aspect of social capacity building both in terms of augmenting people's ability and motivation to act and encouraging participation at the community level (Hoppner et al., 2012). Recent literature on communication and participation stresses that a homogeneous "general public" does not exist and that different population groups may necessitate different communication strategies (see Hoppner et al., 2010, 2012). Communities in flood-risk areas are composed of individuals of varying social and demographic profiles, and these differences are reflected in the complexity and multidimensional nature of the communication process. The READY WebGIS approach, proposed in this paper, should thus be supported by "place-based" methods. For example, the provision and dissemination of information to the broadest target audience possible through public consultation events, in-person information initiatives, or through recognized access points or on-the-ground services, is important. Web-information sources, if they are not published, are not widely known, but they can become better known when visited frequently. Moreover, a two-way communication process is more likely to be effective in this regard since it gives stakeholders a chance to voice concerns and give feedback.

On the one hand, flood-risk agencies and civil protection associations should contribute to the development of selfhelp groups in at-risk communities. This can be achieved by communicating with existing local groups, utilizing on-theground services and holding public stakeholder engagement events. On the other hand, the proposed READY WebGIS approach is a suitable tool for building social capacity both for the sake of encouraging self-protection and stakeholder involvement in management decisions. READY is useful for achieving rapid results for shared understandings of natural risk issues. The interactive, dynamic and flexible nature of the technology, combined with the immediacy with which information is presented by the map and graphic symbols, can facilitate and increase the speed of knowledge acquisition. READY can provide visual and symbolic information that is simple both to understand and adopt. The READY framework is able to present information that is relevant to the user's location, enhancing the user's ability to adequately respond.

In addition, READY can operatively support a regular and ongoing information campaign that is more efficient than the one-off information campaigns (O'Sullivan et al., 2012) that are typically performed by TV and radio. The latter communication media, together with existing robust procedure systems (i.e. warning systems and emergency assistance plans) are more efficient than WebGIS during crisis emergency management and during floods when real-time services are 


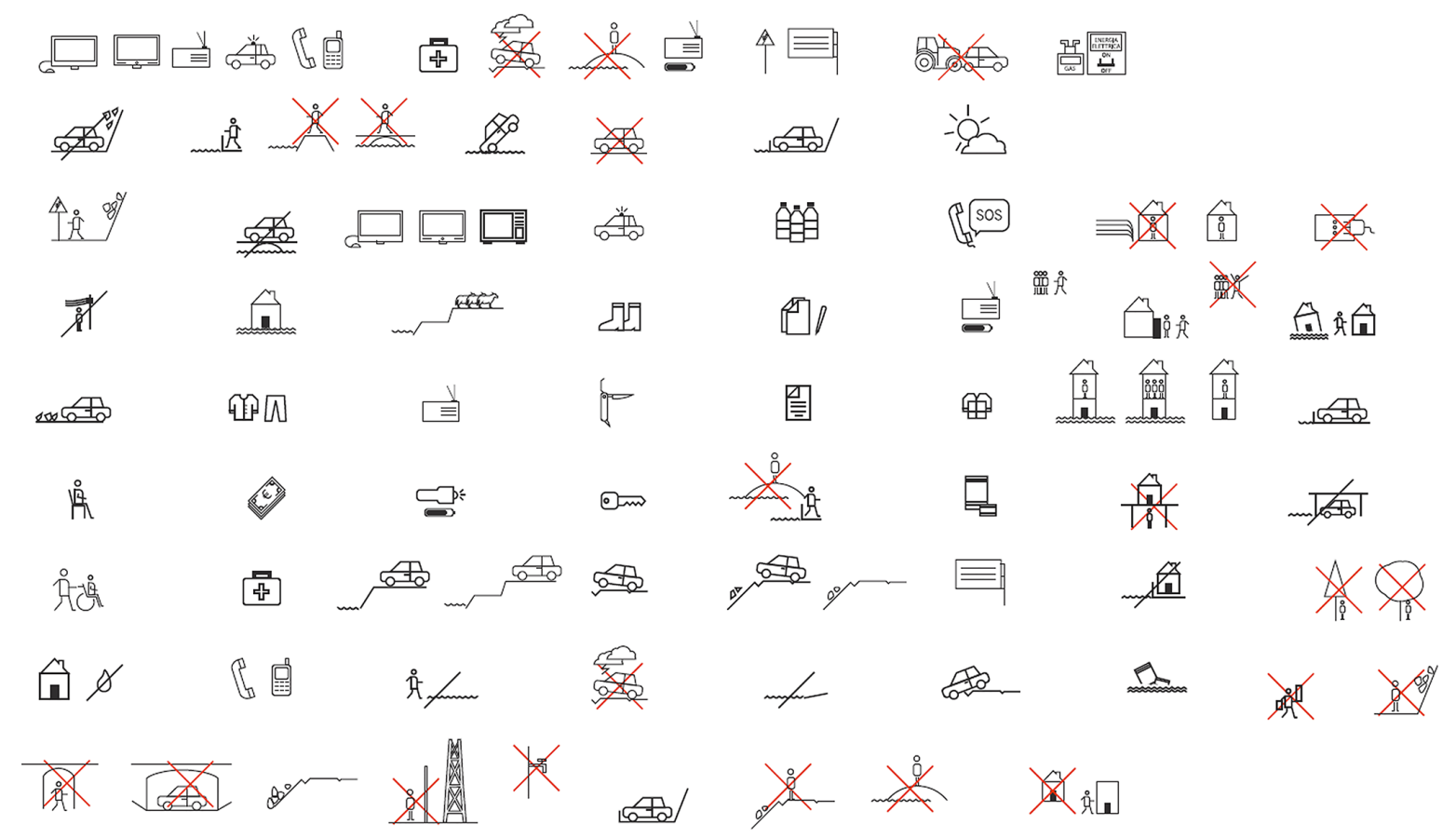

Figure 14. System of graph symbols, proposed in the READY project, for the communication of self-protection behaviour actions in case of alert.

needed. In the same way, while information published online tends to be less time- and resource-intense than "placebased" methods (e.g. public meetings and participatory exercises), it can be less effective in motivating personal action, reducing peoples' focus on technical measures (Wachinger et al., 2012). In contrast, WebGIS is highly relevant in the prevention, mitigation and preparedness phases (Le Cozannet et al., 2014). READY WebGIS is needed to provide stakeholders with information about hazards, vulnerability and exposure assessments for evacuation procedures. These measures increase the capacity of stakeholders to protect their own lives, the lives of their family and their property. Preparedness advice was found to reinforce the economic savings that could be achieved from the implementation of lowcost, reasonably simple self-protection measures (O'Sullivan et al., 2012). Therefore, when asked who can create such a system, governance agencies, private associations and interested citizens should be informed that resilient communities can save money by adopting these prevention techniques. Disseminating information can raise awareness about risks and encourage efforts to mitigate those risks to stakeholders and property. The process of transforming information into knowledge should be supported by an integrated and multidimensional communication system in which traditional and innovative communications methods coexist.

\section{Conclusions}

Current research is mainly focused on the development of large geo-information architectures and services (e.g. GEOSS). These platforms remain an essential part of the innovation and diffusion of Earth observation instruments. However, site-specific applications could ensure their connection with users. Indeed, it is necessary to tailor communication to site-specific users due to the different risk culture and experience of citizens. In this paper, a WebGIS was proposed for visualization and easy querying of a complex flood hazard and risk database. It allows users to explore alternative scenarios or historic calamitous events with the goal of building capacity within the general public to prepare themselves for flood events. It has been designed by a cross-disciplinary group of experts specifically for experimental application in the Basilicata region of Italy. However, the method and tools outlined here may have applicability to other systems and other regions.

A new technology is presented that, supported by "placebased" methods, could enhance citizen understanding of flood risks. This could in turn result in increased public awareness and, hence, increase the resilience of the whole community to cope with flood events. As Wood (2003) says, getting map-making tools in the hands of more people is a good thing because map making requires spatial thinking, and the world definitely needs more of that.

Future developments of the proposed model could beneficially explore the development of a mobile platform for 
smartphones and tablets with a flowing and intuitive interface.

Acknowledgements. We thank the group of experts who participated to the design of the WebGIS. Particular thanks are owed to S. Manfreda (University of Basilicata), L. Giuzio (Wat-TUBE srl), A. Presta (Lacosa srl), M. Maggio and G. Albano (Paesit srl) for their most active participation.

Edited by: Kang-tsung Chang

Reviewed by: two anonymous referees

\section{References}

Albano, R., Sole, A., Adamowski, J., and Mancusi, L.: A GIS-based model to estimate flood consequences and the degree of accessibility and operability of strategic emergency response structures in urban areas, Nat. Hazards Earth Syst. Sci., 14, 2847-2865, doi:10.5194/nhess-14-2847-2014, 2014.

AVI ("Aree Vulnerate Italiane") project, inventory of areas affected by landslides and floods in Italy from 1918 to 2000, available at: http://avi.gndci.cnr.it/, Department of Civil Protection to the National Group for Prevention of Hydrological Hazards (GNDCI) of the National Research Council IRPI ("Istituto Nazionale per la Protezione Idrogeologica"), Italy, 2000.

Berkes, F.: Understanding uncertainty and reducing vulnerability: lessons from resilience thinking, Nat. Hazards, 41, 283-295, 2007.

Büchele, B., Kreibich, H., Kron, A., Thieken, A., Ihringer, J., Oberle, P., Merz, B., and Nestmann, F.: Flood-risk mapping: contributions towards an enhanced assessment of extreme events and associated risks, Nat. Hazards Earth Syst. Sci., 6, 485-503, doi:10.5194/nhess-6-485-2006, 2006.

Douglas, J., Uslaender, T., Schimak, G., Esteban, J. F., and Denzer, R.: An open distributed architecture for sensor networks for risk management, Sensors, 8, 1755-1773, 2008.

Dovers, S. R. and Handmer, J. W.: Uncertainty, sustainability and change, Global Environ. Change, 2, 262-276, 1992.

EC: Directive 2007/60/EC of the European Parliament and of the Council of the European Union of 23 October 2007 on the assessmet and management of food risk, Strasbourg, 2007.

Folke, C.: Resilience: The emergence of a perspective for socialecological system analyses, Global Environ. Change, 16, 253267, 2006.

Folke, C., Hahn, T., Olsson, P., and Norberg, J.: Adaptive governance of social-ecological systems, Ann. Rev. Environ. Resour., 30, 441-473, 2005.

Frigerio, S. and Van Westen, C. J.: RiskCity and WebRiskCity: Data Collection, Display, and Dissemination in a Multi-Risk Training Package, Cartogr. Geogr. Inf. Sci., 37, 119-135, 2010.

Fuchs, S. and Holub M.: Risk management strategies for landslides in European mountain regions - Current practice in Austria and future needs, Revista Forum Geogr., 6, 5-21, 2007.

Fuchs, S., Spachinger, K., Dorner, W., Rochman, J., and Serrhini, K.: Evaluating cartographic design in flood risk mapping, Environ. Haz., 8, 52-70, 2009.
Hoppner, C., Brundl, M., and Buchecker, M.: Risk communication and natural hazards, CapHaz-Net WP5 Report, Swiss Federal Research Institute WSL, available at: http://caphaz-net.org/ outcomes-results/CapHaz-Net_WP5_Risk-Communication.pdf (last access: 18 October 2011), 2010.

Hoppner, C., Whittle, R., Brundl, M., and Buchecker, M.: Linking social capacities and risk communication in Europe: a gap between theory and practice?, Nat. Hazards, 64, 1753-1778, 2012.

IPCC (International Panel on Climate Change: Climate Change): Impacts, Adaptation and Vulnerability, Contribution of the Working Group II to the Fourth Assessment Report of the Intergovernmental Panel on Climate Change, 2007.

Kjellgren, S.: Exploring local risk managers' use of flood hazard maps for risk communication purposes in BadenWürttemberg, Nat. Hazards Earth Syst. Sci., 13, 1857-1872, doi:10.5194/nhess-13-1857-2013, 2013.

Klein, R. J. T., Nicholls, R. J., and Thomalla, F. T.: Resilience to natural hazards: how useful is the concept?, Environ. Haz., 5, 35-45, 2003.

Kos, A.: Developing capacity for natural hazard management using an active learning approach and web-based geographical information, Nat. Hazards Earth Syst. Sci., 9, 85-95, doi:10.5194/nhess-9-85-2009, 2009.

Le Cozannet, G., Bagni, M., Thierry, P., Aragno, C., and Kouokam, E.: WebGIS as boundary tools between scientific geoinformation and disaster risk reduction action in volcanic areas, Nat. Hazards Earth Syst. Sci., 14, 1591-1598, doi:10.5194/nhess-141591-2014, 2014.

Meyer, V., Kuhlicke, C., Luther, J., Fuchs, S., Priest, S., Dorner, W., Serrhini, K., Pardoe, J., McCarthy, S., Seidel, J., Palka, G., Unnerstall, H., Viavattene, C., and Scheuer, S.: Recommendations for the user-specific enhancement of flood maps, Nat. Hazards Earth Syst. Sci., 12, 1701-1716, doi:10.5194/nhess-121701-2012, 2012.

Müller, M., Vorogushyn, S., Maier, P., Thieken, A. H., Petrow, T., Kron, A., Büchele, B., and Wächter, J.: CEDIM Risk Explorer a map server solution in the project "Risk Map Germany", Nat. Hazards Earth Syst. Sci., 6, 711-720, doi:10.5194/nhess-6-7112006, 2006.

O’Sullivan, J. J., Bradford, R. A., Bonaiuto, M., De Dominicis, S., Rotko, P., Aaltonen, J., Waylen, K., and Langan, S. J.: Enhancing flood resilience through improved risk communications, Nat. Hazards Earth Syst. Sci., 12, 2271-2282, doi:10.5194/nhess-122271-2012, 2012.

Planat: Hochwassergefahren in der Schweiz: Risikobewusstsein in der Bevölkerung und die Implikationen für eine erfolgreiche Risikokommunikation, Planat, c/o Bundesamt für Wasser und Geologie, available at: http://www.planat.ch/fileadmin/ PLANAT/planatpdf/alle/R0483d.pdf (last access: 2 July 2012), 2004.

Renn, O.: Risk governance: coping with uncertainty in a complex world, Earthscan, London, 2008.

Sene, K.: Flood Warning, Forecasting and Emergency Response, Springer, Berlin, 2008.

Shen, X.: Flood risk perception and communication in different cultural contexts-a comparative case study between Wuhan, China and Cologne, Germany, Ph.D. Dissertation, University of Bonn, 2009. 
Steen, M., Kuijt-Evers, L., and Klok, J.: Early user involvement in research and design projects - a review of methods and practices. 23rd EGOS Colloquium (European Group for Organizational Studies) 5-7 July, 2007, Vienna, 2007.

Thieken, A. H., Mariani, S., Longfield, S., and Vanneuville, W.: Preface: Flood resilient communities - managing the consequences of flooding, Nat. Hazards Earth Syst. Sci., 14, 33-39, doi:10.5194/nhess-14-33-2014, 2014.

Vicari, A., Bilotta, G., Bonfiglio, S., Cappello, A., Ganci, G., Herault, A., Rustico, E., Gallo, G., and Del Negro, C.: LAV@HAZARD: a web-GIS interface for volcanic hazard assessment, Annals Geophys., 54, 662-670, doi:10.4401/ag-5347, 2011.
Wachinger, G., Renn, O., Begg, C., and Kuhlicke, C.: The risk perception paradox: implications for governance and communication of natural hazards, Risk Analysis, 33, 1049-1065, 2012.

Watts, M. J. and Bohle, H. G.: The space of vulnerability: the causal structure of hunger and famine, Prog. Human Geog., 17, 43-67, 1993.

Wood, D.: Cartography is dead (Thank God!), Cartogr. Perspect., 45, 4-7, 2003. 